\title{
IGF1 potentiates the pro-inflammatory response in human peripheral blood mononuclear cells via MAPK
}

\author{
Thalijn Liliana Catharina Wolters, Mihai Gheorghe Netea, \\ Adrianus Rudolfus Marinus Maria Hermus, Johannes Willem Adriaan Smit and \\ Romana Teodora Netea-Maier
}

Department of Internal Medicine, Radboud University Medical Center, Nijmegen, The Netherlands
Correspondence should be addressed to R T Netea-Maier Email

Romana.Netea-Maier@ radboudumc.nl

\begin{abstract}
Acromegaly is characterized by growth hormone $(\mathrm{GH})$ and insulin-like growth factor 1 (IGF1) excess and is accompanied by an increased cardiovascular diseases (CVD) risk. As innate immune responses are crucial in CVD development, and IGF1 is linked to subclinical inflammation, we hypothesized that GH/IGF1 excess contributes to CVD development by potentiating systemic inflammation. We aimed to assess the effects of GH/IGF1 on inflammatory cytokine production. Whole blood from acromegaly patients and healthy volunteers and peripheral blood mononuclear cells (PBMCs) from healthy volunteers were stimulated with Toll-like receptor (TLR) ligands, with or without adding GH or IGF1 (in PBMC). Cytokine concentrations were measured by ELISA. The underlying signalling pathways were investigated by the inhibition of downstream targets of the IGF1 receptor. The following results were obtained. GH or IGF1 alone did not influence cytokine production in PBMCs. GH did not affect TLR-induced cytokine production, but co-stimulation with IGF1 dose dependently increased the TLR ligand-induced production of IL6 $(P<0.01)$, TNF alpha $(P=0.02)$ and IFNg $(P<0.01)$, as well as the production of the anti-inflammatory cytokine IL10 $(P=0.01)$. IGF1 had no effect on IL1B, IL17 and IL22 production. Inhibition of the MAPK pathway, but not mTOR, completely abrogated the synergistic effect of IGF1 on the LPS-induced IL6 and TNF alpha production. In whole blood of acromegaly patients, ex vivo IL6 production was increased $(P<0.01)$. In conclusion, IGF1, but not GH, has pro-inflammatory effects, probably via the MAPK signalling pathway and might be involved in the pathogenesis of atherosclerosis in acromegaly. The increased IL10 production possibly counteracts the pro-inflammatory effects.
\end{abstract}

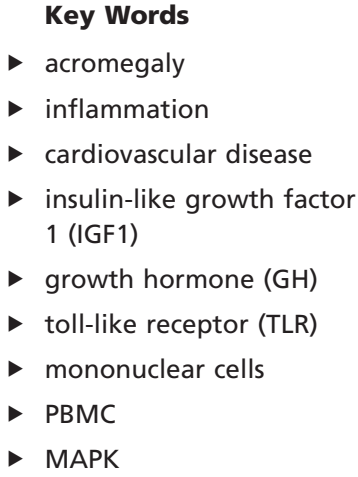

Journal of Molecular Endocrinology (2017) 59, 129-139

\section{Introduction}

Acromegaly is an endocrine disease characterized by overproduction of growth hormone $(\mathrm{GH})$, which is in the majority of cases caused by a GH-producing pituitary adenoma. GH stimulates the endogenous production of
(C) 2017 Society for Endocrinology Printed in Great Britain insulin-like growth factor 1 (IGF1), primarily by the liver, but also (in much lower amounts) in almost every other cell, including immune cells (Kooijman et al. 1992). Most patients with acromegaly are exposed to excessive levels

Published by Bioscientifica Ltd. 
of GH and IGF1 for many years. They are also known to have an increased risk of developing atherosclerosis and CVD (Dekkers et al. 2008).

In the last decades, abundant evidence has become available on the crucial role of inflammation in the pathogenesis of atherosclerosis (Hansson \& Libby 2006). Interestingly, Touskova and coworkers (Touskova et al. 2012) recently suggested a regulatory role of IGF1 in the development of subclinical inflammation through the pro-inflammatory activation of peripheral monocytes. IGF1 has been suggested to modulate the human immune response (Weigent 2013, Higashi et al. 2014) and a proinflammatory state with higher concentrations of TNF alpha and IL8 is present in acromegaly (Arikan et al. 2009). Moreover, a recent study found positive correlations between IGF1 levels and two markers of inflammation: neutrophil-to-lymphocyte ratio and platelet-tolymphocyte ratio (Ucler et al. 2015).

Based on these findings, it may be hypothesized that prolonged exposure of immune cells to increased GH and IGF1 levels induces a pro-inflammatory state that contributes to the development of cardiovascular diseases (CVD) in acromegaly. Few studies have assessed the direct effects of GH and/or IGF1 on cytokine production (Renier et al. 1996, Kooijman \& Coppens 2004). The immune-modulating effects of IGF1 have been described in various types of immune cells, mainly in lymphocytes (Imperlini et al. 2015) and monocytes (Renier et al. 1996), with both pro- and anti-inflammatory effects being reported (Higashi et al. 2014): the final effect depends on the administered dose of IGF1, the nature of the (co) stimulus and the type of immune cell involved. However, the majority of these studies were performed before the discovery of activation of inflammation by pathogen recognition receptors, such as Toll-like receptors (TLRs) (Akira 2001), and before the role of T-helper cell (Th) subsets in atherosclerosis (Robertson \& Hansson 2006) was elucidated. Therefore, the exact mechanisms by which GH and/or IGF1 could influence inflammatory cells are not completely understood.

The hypothesis of this study is that supraphysiological levels of IGF1 have pro-inflammatory effects on circulating immune cells, which may contribute to the well-known increased risk of CVD and insulin resistance in acromegaly patients (Che et al. 2002, Ucler et al. 2015). In this study, we aimed to comprehensively assess the effects of GH and IGF1 on TLR ligand-induced cytokine production in immune cells. We therefore set out to assess both monocyte-derived and Th-derived cytokine production and the signalling pathways that are involved in these processes.
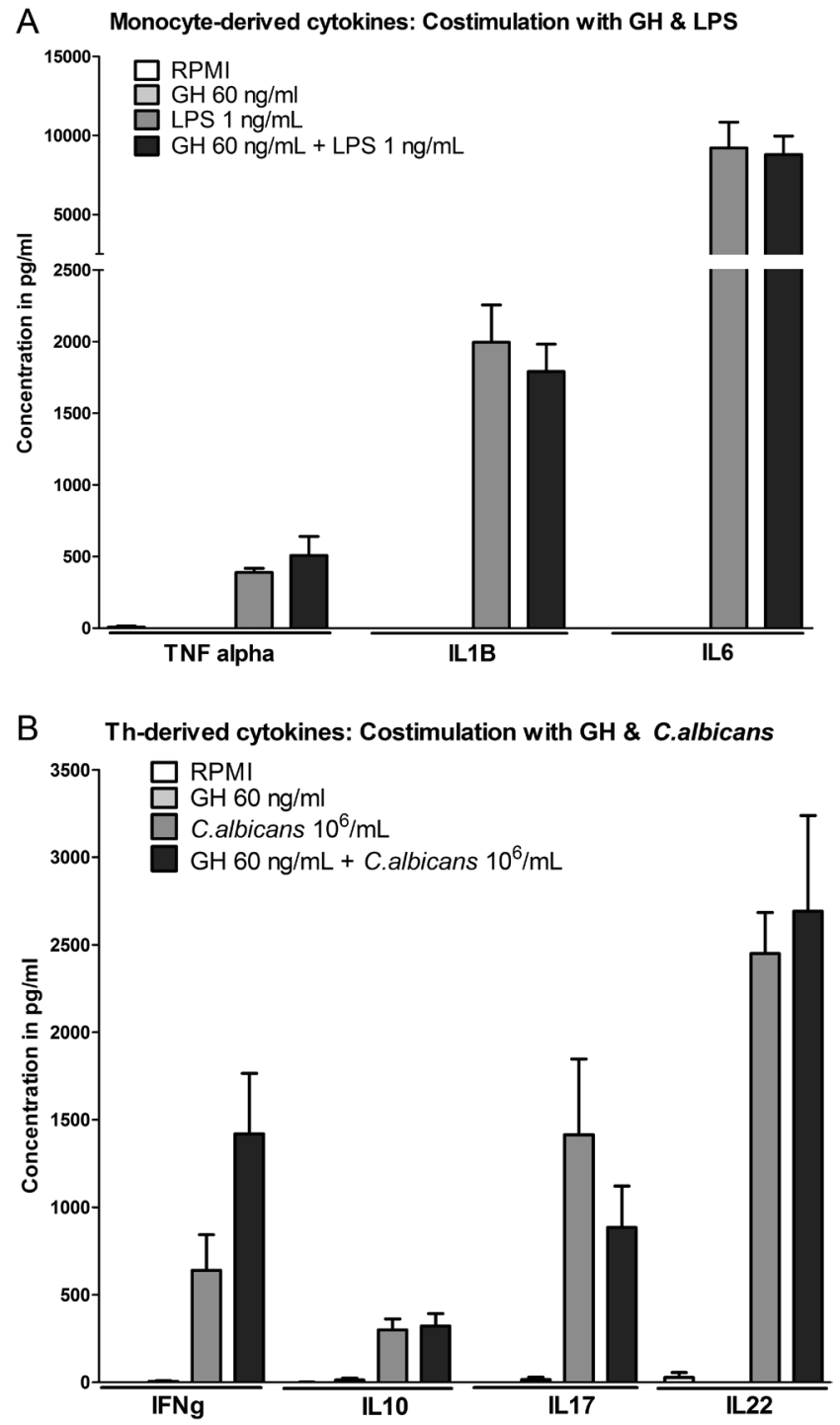

Figure 1

Effects of GH on the ex vivo (A) monocyte-derived $(n=12)$ and (B) T cell-derived $(n=6)$ cytokine production in PBMCs from healthy volunteers. Cytokine levels are displayed in $\mathrm{pg} / \mathrm{mL}$. Statistical analyses were performed using the Wilcoxon matched-pairs signed-rank test. $P$ values $<0.05$ are considered statistically significant. ${ }^{*} P<0.05 ; * \star P<0.01$. C. albicans, Candida albicans heat-killed conidia; GH, growth hormone; IFNg, interferon gamma, IL, interleukin; LPS, lipopolysaccharide; PBMC, peripheral blood mononuclear cell; P3C, Pam3Cys; RPMI, Roswell Park Memorial Institute (medium); TNF alpha, tumour necrosis factor alpha.
() 2017 Society for Endocrinology Printed in Great Britain
Published by Bioscientifica Ltd 


\section{Materials and methods}

\section{Reagents and microorganisms}

TLR2 ligand Pam3Cys was purchased from InvivoGen (San Diego, CA, USA) and used in a concentration $10 \mathrm{ng} / \mathrm{mL}$. E. coli LPS (serotype 055:B5) was purchased from Sigma-Aldrich, repurified as previously described and used as an ultrapure TLR4 ligand (Hirschfeld et al. 2001) in a concentration of $1 \mathrm{ng} / \mathrm{mL}$ for peripheral blood mononuclear cells (PBMCs) and $100 \mathrm{ng} / \mathrm{mL}$ for whole blood (WB). For the stimulation of Th cells, Candida albicans ATCC MYA-3573 (UC 820), a strain well described elsewhere (Lehrer \& Cline 1969), was used. C. albicans was grown overnight in Sabouraud broth at $37^{\circ} \mathrm{C}$, whereafter cells were harvested by centrifugation, washed twice and resuspended in Roswell Park Memorial Institute (RPMI) 1640 culture medium (Dutch Modification, Gibco, Thermo Scientific) (van der Graaf et al. 2005). C. albicans yeasts were heat-killed for $30 \mathrm{~min}$ at $95^{\circ} \mathrm{C}$; all stimulations with C. albicans conidia were with a concentration of $10^{6} / \mathrm{mL}$. All mentioned concentrations are the final concentrations that are present in the well.
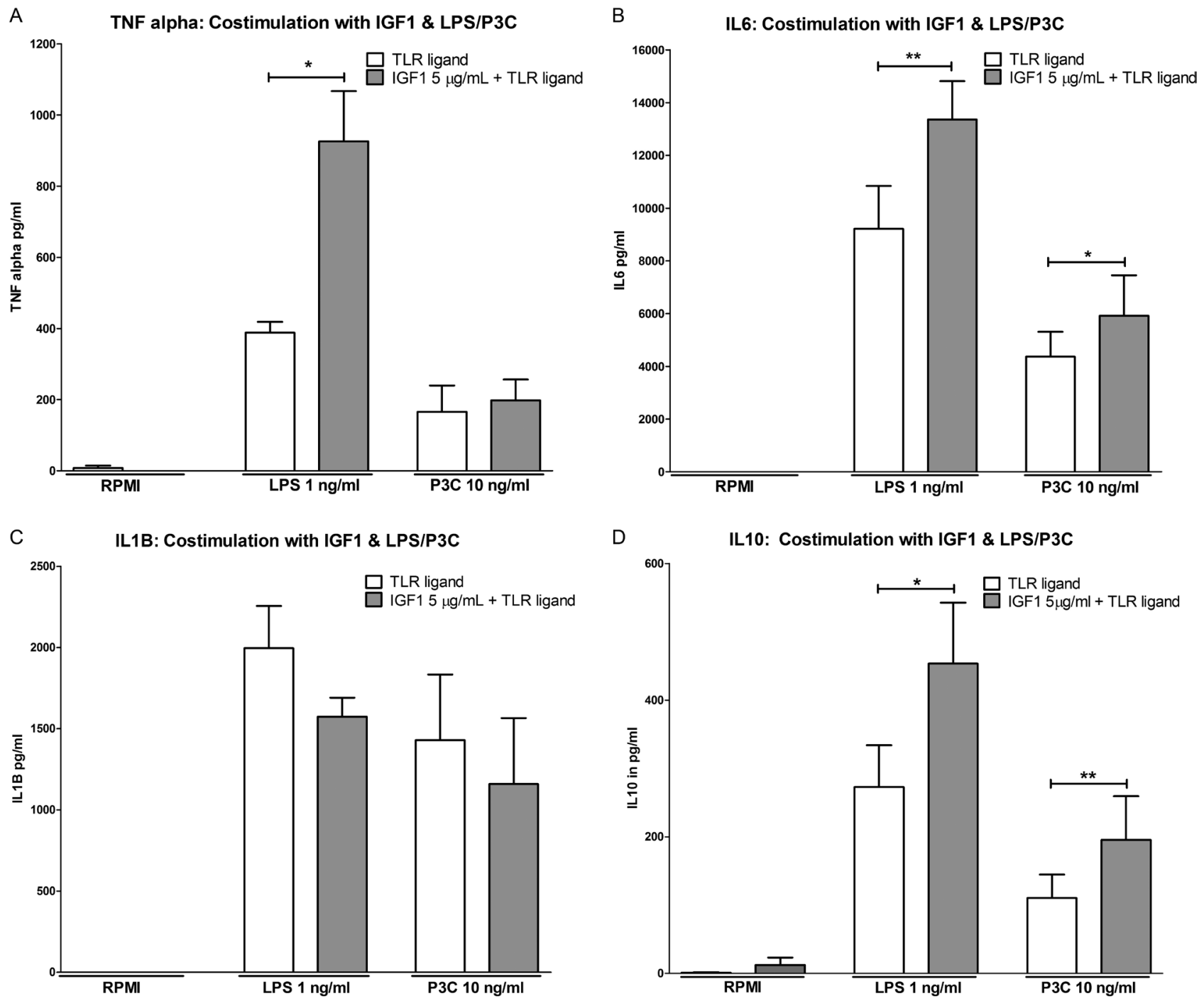

Figure 2

Effects of IGF1 on the ex vivo monocyte-derived cytokine production in PBMCs from healthy volunteers $(n=12)$. (A) TNF alpha, (B) IL6, (C) IL1B and (D) IL10. Cytokine levels are displayed in $\mathrm{pg} / \mathrm{mL}$. Analyses were performed using the Wilcoxon matched-pairs signed-rank test. $P$ values $<0.05$ are considered statistically significant. ${ }^{*} P<0.05$; ${ }^{*} P<0.01$. IGF1, insulin-like growth factor 1 ; IL, interleukin; LPS, lipopolysaccharide; PBMC, peripheral blood mononuclear cell; P3C, Pam3Cys; RPMI, Roswell Park Memorial Institute (medium); TNF alpha, tumour necrosis factor alpha. 


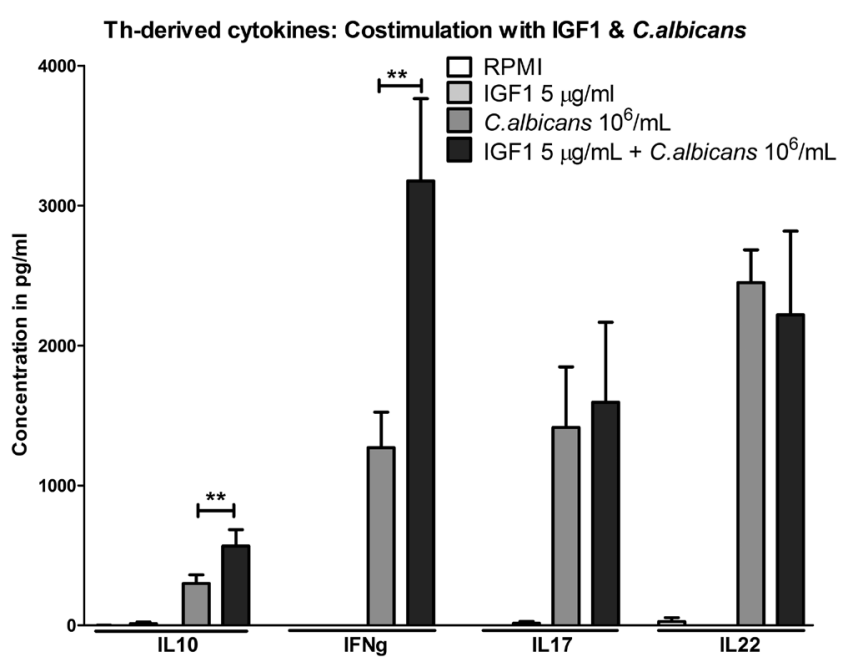

Figure 3

Effects of IGF1 on the ex vivo T-cell-derived cytokine productions in PBMCs from healthy volunteers $(n=8)$. Cytokine levels are displayed in $\mathrm{pg} / \mathrm{mL}$. Analyses were performed using the Wilcoxon matched-pairs signed-rank test. $P$ values $<0.05$ are considered statistically significant. ${ }^{*} P<0.05 ; * * P<0.01$. C. albicans, Candida albicans heat-killed conidia; IFNg, interferon gamma; IGF1, insulin-like growth factor 1; IL, interleukin; PBMC, peripheral blood mononuclear cell; RPMI, Roswell Park Memorial Institute (medium).

\section{Subjects}

Human PBMCs were obtained from buffy coats of healthy blood donors (Sanquin Blood bank, Amsterdam, The Netherlands). Whole blood (WB) was obtained from healthy volunteers ( $n=24 ; 10$ males, 14 females) and from consecutive patients with active acromegaly $(n=12$; 7 males, 5 females), who visited the outpatient clinic of the division of Endocrinology in the Radboud University Medical Center Nijmegen, the Netherlands. All patients had a biochemically confirmed diagnosis of acromegaly and elevated IGF1 levels ( $\geq 2.4-19.6$ s.D.; corrected for sex and age) upon participation. Exclusion criteria included use of statins or other anti-inflammatory drugs and presence of active infectious or inflammatory diseases or malignancies. This study was conducted in accordance with the Declaration of Helsinki and approved by the Ethics committee of our institution (CMO 2010/104; CMO 2012/131). All participants signed informed consent prior to participation in this study.

\section{In vitro stimulation of human PBMCs}

Separation and stimulation of PBMCs was performed as described previously (Endres et al. 1988, Netea et al. 2006). In short, the PBMC fraction was obtained by density centrifugation of diluted blood (one part blood to one part pyrogen-free saline) over Ficoll-Paque (GE Healthcare). Cells were washed twice in saline and suspended in RPMI1640 culture medium supplemented with gentamicin $0.105 \mathrm{mmol} / \mathrm{L}$ (Centrafarm, Etten-Leur, The Netherlands), Glutamax $2 \mathrm{mmol} / \mathrm{L}$ (Gibco, Thermo Scientific) and pyruvate $1 \mathrm{mmol} / \mathrm{L}$ (Gibco, Thermo Scientific). The cells were counted in a Coulter counter, and their number was adjusted to $5 \times 106$ cells $/ \mathrm{mL}$. Five hundred thousand PBMCs in a volume $100 \mu \mathrm{L}$ were incubated at $37^{\circ} \mathrm{C}$ in round-bottom 96-well plates (Greiner; Kremsmünster, Austria) with a total added volume of $100 \mu \mathrm{L}$ of stimulus (TLR ligand, GH or IGF1) or RPMI (negative control) per well. GH (R\&D systems) was used in concentrations of $0.6,6,60$ and $600 \mathrm{ng} / \mathrm{mL}\left(2.73 \times 10^{-2}, 2.73 \times 10^{-1}, 2.73\right.$ and $27.3 \mathrm{pmol} / \mathrm{mL}$ ) and IGF1 (R\&D Systems) was used in concentrations of $0.05,0.5$ and $5 \mu \mathrm{g} / \mathrm{mL}(6.536,65.36$ and $653.6 \mathrm{nmol} / \mathrm{L})$. In separate experiments, aimed to assess the effects of different signalling pathways, Five hundred thousand PBMCs in a volume $50 \mu \mathrm{L}$ were preincubated for $30 \mathrm{~min}$ with either $50 \mu \mathrm{L}$ of the mTOR-inhibitor rapamycin $0.1 \mu \mathrm{mol} / \mathrm{L}$ (R0395; Sigma-Aldrich) or the MAPK/extracellular signal-regulated kinase (ERK) kinase (MEK)-inhibitor U0126 $10 \mu \mathrm{mol} / \mathrm{L}$ (Promega) or dimethyl sulfoxide (DMSO; Cryosure-DMSO >99.9\% USP grade, WAK-Chemie Medical GmbH, Steinbach/Ts., Germany) as a negative control before stimulation with $50 \mu \mathrm{L}$ of either a LPS $1 \mathrm{ng} / \mathrm{mL}$ or RPMI (negative control) and either $50 \mu \mathrm{L}$ of IGF1 $(5 \mu \mathrm{g} / \mathrm{mL})$ or RPMI (negative control). After $24 \mathrm{~h}$ of incubation, supernatants were collected and stored at $-20^{\circ} \mathrm{C}$ until assayed.

\section{Ex vivo stimulation of WB}

Venous blood was drawn in $4 \mathrm{~mL}$ lithium-heparin tubes (Vacutainer, BD; Franklin Lakes, NJ, USA). $100 \mu \mathrm{L}$ of WB was incubated at $37^{\circ} \mathrm{C}$ in 48 -well plates (Greiner) with $400 \mu \mathrm{L}$ of stimulus (LPS $100 \mathrm{ng} / \mathrm{mL}$ or C. albicans $106 / \mathrm{mL}$ or RPMI (negative control) per well (van Crevel et al. 1999). After $24 \mathrm{~h}$ of incubation, supernatants were collected and stored at $-20^{\circ} \mathrm{C}$ until assayed.

\section{Determination of cytokine levels}

Human cytokine concentrations were measured by commercial enzyme-linked immunosorbent assay (ELISA) kits according to the manufacturer's instructions: tumour necrosis factor alpha (TNF alpha), interleukin 1 beta (IL1B), interleukin 17 (IL17), interleukin 22 (IL22) (DuoSet ELISA, R\&D Systems), interleukin 10 (IL10), interleukin 6 (IL6), interferon gamma (IFNg) (PeliKine Compact, Sanquin; 
A

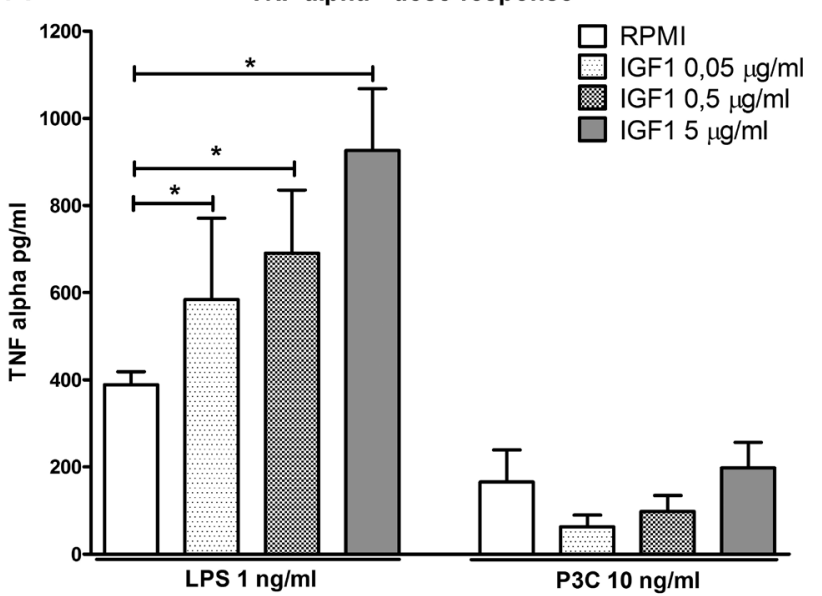

B

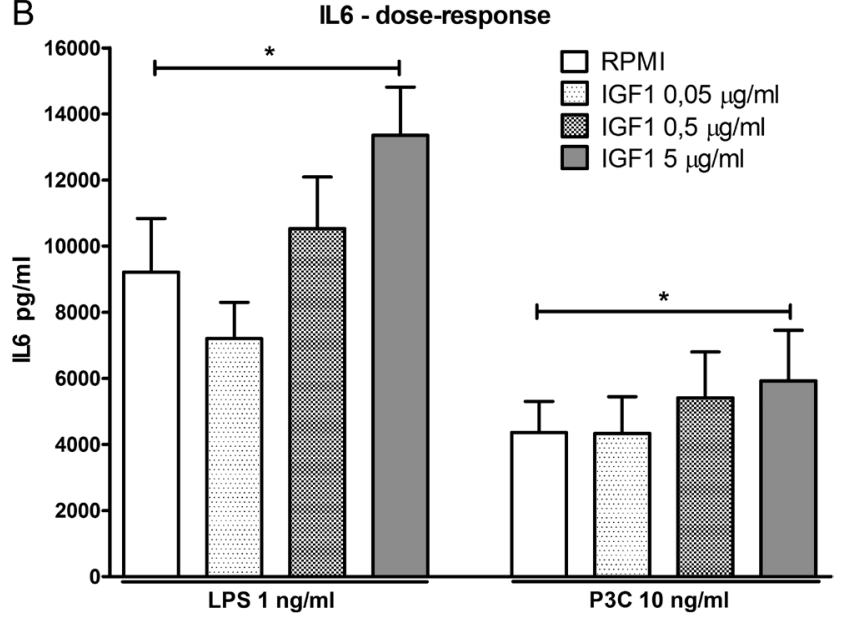

C

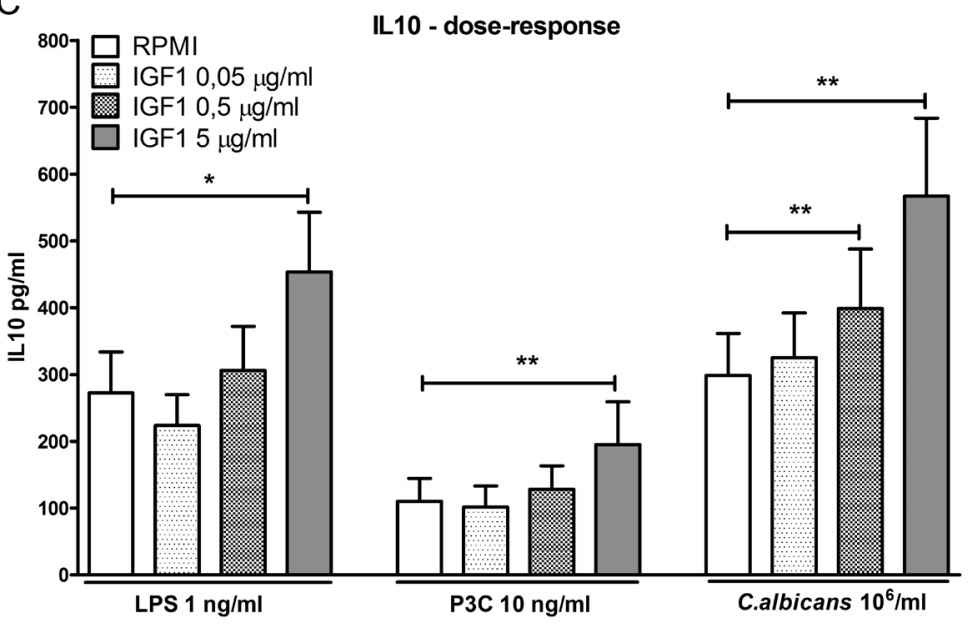

D

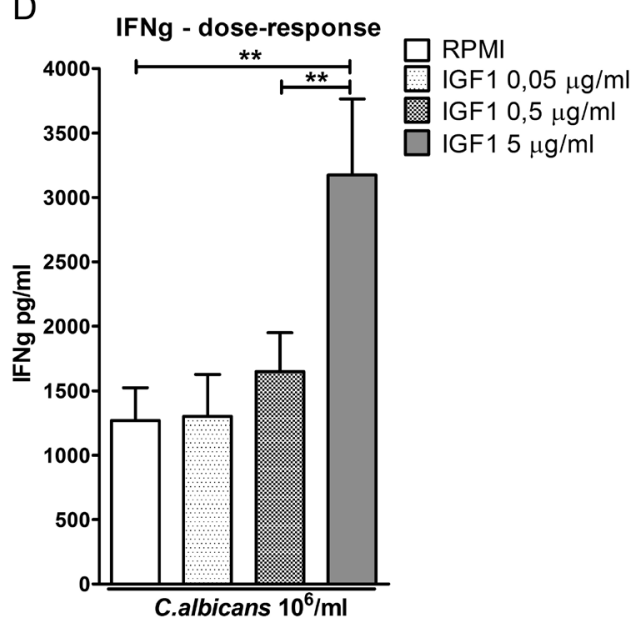

Figure 4

Dose-response curves for stimulation with IGF1 and a TLR ligand resp. C. albicans ( $n=8$ ); (A) TNF alpha, (B) IL6, (C) IL10 and (D) IFNg. Cytokine levels are displayed in $\mathrm{pg} / \mathrm{mL}$. Analyses were performed using the Wilcoxon matched-pairs signed-rank test. $P$ values $<0.05$ are considered statistically significant. ${ }^{*} P<0.05 ; * * P<0.01$. C. albicans, Candida albicans heat-killed conidia; IFNg, interferon gamma; IGF1, insulin-like growth factor 1; IL, interleukin; LPS, lipopolysaccharide; P3C, Pam3Cys; RPMI, Roswell Park Memorial Institute (medium); TLR, toll-like receptor; TNF alpha, tumour necrosis factor alpha.

Amsterdam). The sensitivity of the assays was $1.5 \mathrm{pg} /$ $\mathrm{mL}$ for IL6, $2.34 \mathrm{pg} / \mathrm{mL}$ for IL10, $3.9 \mathrm{pg} / \mathrm{mL}$ for IL1B and IFNg, $7.8 \mathrm{pg} / \mathrm{mL}$ for TNF alpha and IL17 and $15.6 \mathrm{pg} / \mathrm{mL}$ for IL22.

\section{Western blots}

For Western blotting of ERK (total and phosphorylated), $2.5 \times 106$ PBMCs were incubated with either a MEK inhibitor or RPMI in polypropylene tubes for $30 \mathrm{~min}$ at $37^{\circ} \mathrm{C}$. Subsequently, LPS $(1 \mathrm{ng} / \mathrm{mL})$ or RPMI was added, followed by IGF1 $(5 \mu \mathrm{g} / \mathrm{mL})$ or RPMI, and cells were incubated at $37^{\circ} \mathrm{C}$. After $1 \mathrm{~h}$, cells were lysed in $100 \mu \mathrm{L}$ of lysis buffer $(50 \mathrm{mM}$ Tris, $\mathrm{pH} 7.4,150 \mathrm{mmol} / \mathrm{L} \mathrm{NaCl}, 2 \mathrm{mmol} / \mathrm{L}$ EDTA, $2 \mathrm{mmol} / \mathrm{L}$ EGTA, $10 \%$ glycerol (v/v), 1\% Triton
$\mathrm{X}-100$ (v/v), $40 \mathrm{mmol} / \mathrm{L}$ b-glycerophosphate, $50 \mathrm{mmol} / \mathrm{L}$ sodium fluoride, $200 \mathrm{mmol} / \mathrm{L}$ sodium orthovanadate, complete mini EDTA-free protease inhibitor cocktail and PhosSTOP Phosphatase Inhibitor Cocktail (Roche)). Protein concentration was determined by a BCA assay (Pierce BCA assay; Thermo Scientific). Equal amounts of protein were subjected to SDS-PAGE electrophoresis using 4-15\% precast polyacrylamide gels (Mini-protean TGX, Bio-Rad). Primary antibodies (1:1000) in 5\% (w/v) bovine serum albumin (BSA)/TBST (Tris-buffered saline, Tween 20) were incubated overnight at $4^{\circ} \mathrm{C}$. HRP-conjugated anti-rabbit antibody at a dilution of $1: 5000$ in 5\% $(\mathrm{w} / \mathrm{v})$ milk/TBST was used for $1 \mathrm{~h}$ at room temperature. Quantitative assessment of band intensity was performed by Image Lab statistical software (Bio-Rad). The following 
A
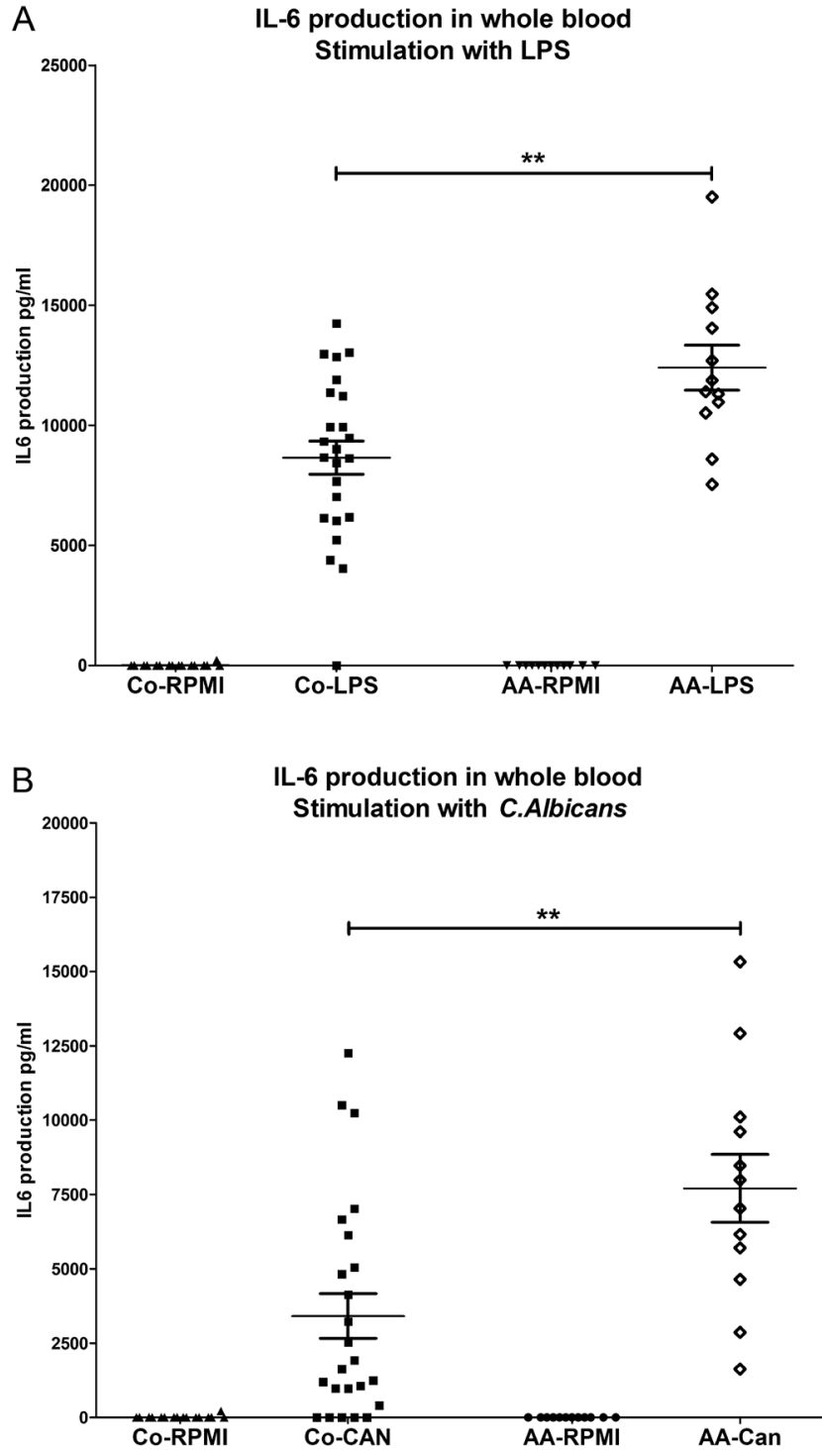

Figure 5

Effects of stimulation with TLR ligands on IL6 production in whole blood obtained from patients with active acromegaly $(n=12)$ and healthy controls ( $n=24)$. (A) LPS, (B) C. albicans. Cytokine levels are displayed in $\mathrm{pg} / \mathrm{mL}$. Analyses were performed using the Mann-Whitney $U$ test. $P$ values $<0.05$ are considered statistically significant. ${ }^{*} P<0.05 ;{ }^{*} P<0.01$. $\mathrm{AA}$, active acromegaly patients; CAN, C. albicans heat-killed conidia; Co, healthy controls; IGF1, insulin-like growth factor 1; IL6, interleukin 6; LPS, lipopolysaccharide; RPMI, Roswell Park Memorial Institute (medium).

antibodies were used: Phospho-p44/42 MAPK (Erk1/2) (Thr202/Tyr204) antibody (Cell Signalling, \#9101) and p44/42 MAPK (Erk1/2) antibody (Cell Signalling, \#9102).

\section{Statistical analysis}

The differences between experimental groups were analysed using the Wilcoxon matched-pairs signed-rank test for PBMC data, and the Mann-Whitney $U$ test for WB data (unless otherwise stated). Statistical analyses were performed with Prism software (version 5.03; GraphPad), which was also used to produce the graphs. Western blots were analysed and quantified using Image Lab 5.0 (build 18 (2013), Bio-Rad). The level of significance was defined as a $P$ value of $<0.05$. Cytokine production in PBMC is plotted as bar charts and cytokine production in WB as dots, both with mean \pm s.E.M. All stimulation experiments were performed at least three times, with a minimum of six volunteers. The Western blot experiments were performed in duplicate.

\section{Results}

\section{Effects of GH on cytokine production}

In our research model, stimulation of PBMCs with different concentrations of GH did not induce monocytederived (TNF alpha, IL6, IL1B) or Th-derived (IFNg, IL17, IL22) pro-inflammatory cytokine production, nor did it induce the production of the anti-inflammatory cytokine IL10. In addition, in PBMCs stimulated with various TLRagonists or microorganisms (LPS, Pam3Cys, C. albicans), co-stimulation with GH did not influence cytokine production (Fig. 1).

\section{Effects of IGF1 on cytokine production}

Stimulation with IGF1 alone did not induce inflammatory cytokine production in PBMCs (data not shown). However, IGF1 potentiated LPS-induced TNF alpha production (Fig. 2A) and LPS-induced and Pam3Cysinduced IL6 production (Fig. 2B) in PBMCs obtained from healthy volunteers. IGF1 did not significantly affect the TLR-induced IL1B production (Fig. 2C). In Th, IGF1 potentiated $C$. albicans-induced IFNg production, but had no effect on IL17 and IL22 production (Fig. 3). In addition, IGF1 stimulation led to a significant increase in the TLR-induced production of the anti-inflammatory cytokine IL10 (Fig. 2D). These effects are dose dependent, since cytokine production increases with higher doses of IGF1 (Fig. 4).

\section{IL-6 production in WB from acromegaly patients}

In WB obtained from acromegaly patients, an increased IL6 production on stimulation with LPS (Fig. 5A) and C. albicans (Fig. 5B) was observed, compared to healthy controls. 
Signalling mechanisms involved in the effects of IGF1 on cytokine production.

To further investigate the mechanisms through which IGF1 influences cytokine production, specific intracellular signalling pathways were inhibited. First, the mTOR-inhibitor rapamycin was used to investigate the PI3K-Akt-mTOR pathway, which is known to be an important intracellular pathway induced by IGF1 and which is also known to modulate cytokine production in monocytes and T-helper cells. Pre-incubation with rapamycin did not affect TNF alpha (Fig. 6A) production or IL6 production (Fig. 6B) in PBMC stimulated with LPS and IGF1. Second, the MEK-inhibitor U0126 was used to investigate the role of the MAPK pathway, another important intracellular signalling pathway for the stimulation of cytokine production. Indeed, inhibition of MAPK pathway by U0126 completely abrogated the synergistic effect of IGF1 on the TNF alpha (Fig. 7A) and IL6 (Fig. 7B) production induced by LPS, suggesting an important role of this pathway for the effects of IGF1. These findings were confirmed by a reduced expression of phosphorylated ERK1/2 (pERK1/2; Fig. 7B) in PBMCs stimulated with LPS and IGF1, after pre-incubation with
U0126. ERK1/2 is a downstream target of MEK, which was inhibited by U0126.

\section{Discussion}

Patients with acromegaly have an increased risk of atherosclerosis and CVD; low-grade inflammation is hypothesized to play an important role in these diseases. In this study, we report that IGF1, present in high circulating concentrations in patients with active acromegaly, potentiates the microbial TLR ligand-induced inflammatory cytokine production. This observed effect of IGF1 on the production of monocyte-derived proinflammatory cytokines is supported by earlier studies (Renier et al. 1996, Tu et al. 1999) and by WB stimulation data from patients with active acromegaly. In contrast, no effects of IGF1 on basal or TLR ligand-induced production of IL1B, IL17 or IL22 were observed. Interestingly, exposure of immune cells to GH did not influence basal or TLR ligand-induced cytokine production. In addition, the MAPK pathway mediates, at least partially, the abovementioned stimulatory effects of IGF1 on monocytederived pro-inflammatory cytokine production. These
A

mTor Inhibition LPS-induced TNF alpha production
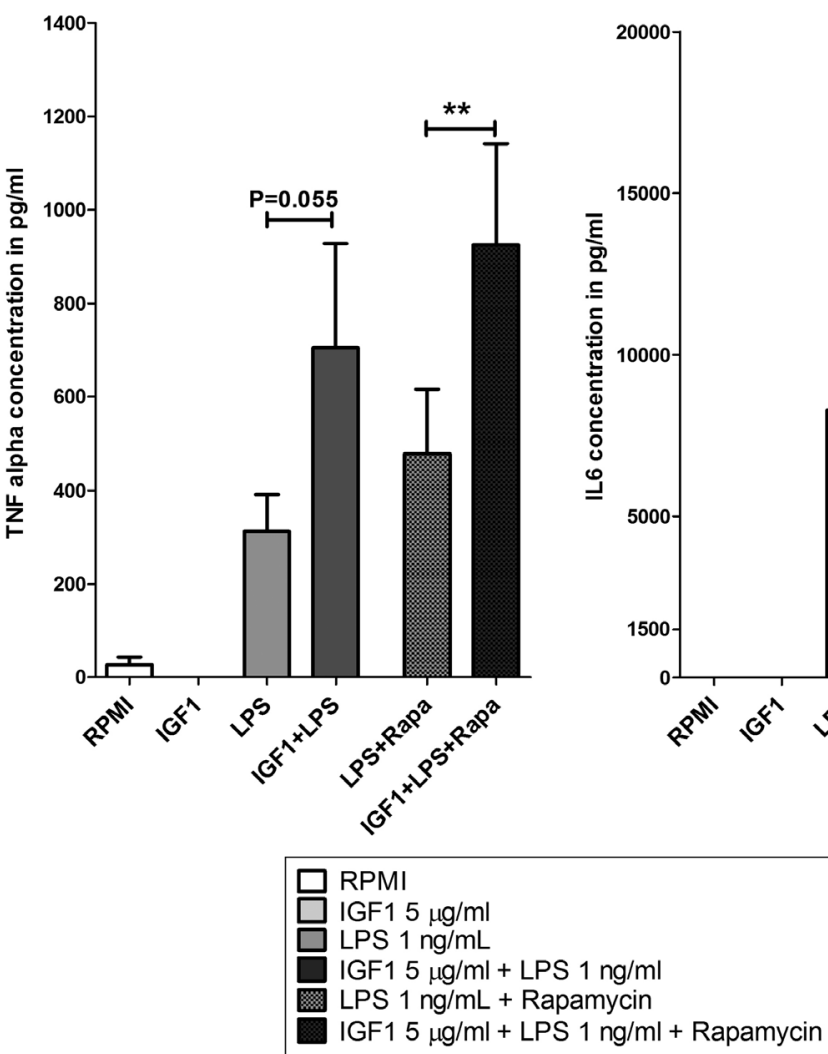

B

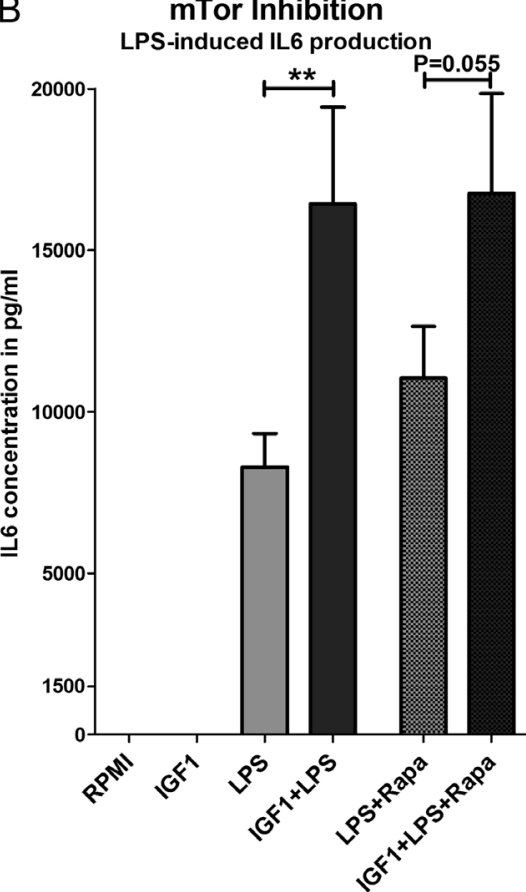

Figure 6

Effects of inhibition of mTor (rapamycin $0.1 \mu \mathrm{M}$ ) signalling pathways on monocyte-derived cytokine production induced by IGF1 $5 \mu \mathrm{g} / \mathrm{mL}$ and LPS $1 \mathrm{ng} / \mathrm{mL}(n=8)$. (A) TNF alpha, (B) IL6. Cytokine levels are displayed in $\mathrm{pg} / \mathrm{mL}$. Analyses were performed using the Wilcoxon matched-pairs signed-rank test. $P$ values $<0.05$ are considered statistically significant. ${ }^{*} P<0.05 ;{ }^{*} P<0.01$. IGF1 insulin-like growth factor 1; IL, interleukin; LPS, lipopolysaccharide; Rapa, rapamycin; RPMI, Roswell Park Memorial Institute (medium); TNF alpha, tumour necrosis factor alpha. 
A
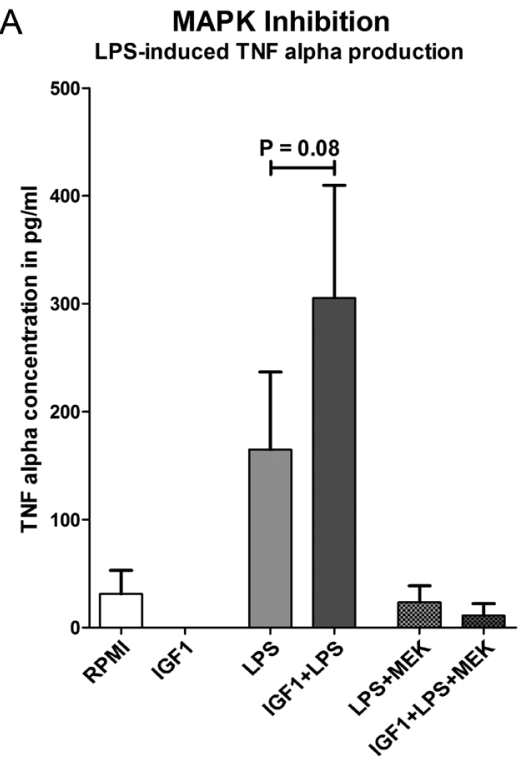

B MAPK Inhibition

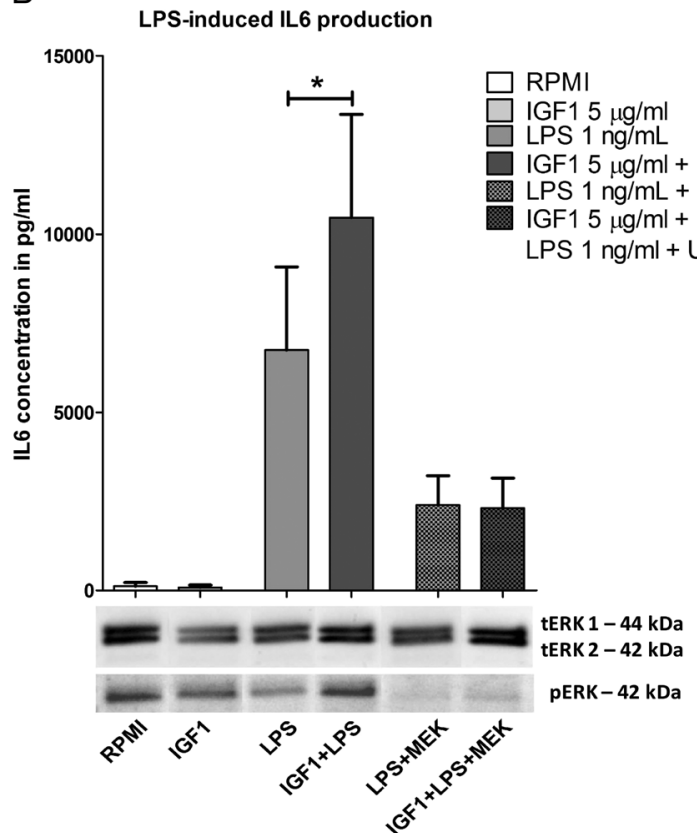

Figure 7

Effects of inhibition of MAPK (U0126 $10 \mu \mathrm{M})$ signalling pathways on pERK/tERK expression (Western blot) and monocyte-derived cytokine production induced by IGF1 $5 \mu \mathrm{g} / \mathrm{mL}$ and LPS $1 \mathrm{ng} / \mathrm{mL}(n=8)$. (A) TNF alpha, (B) IL6. Cytokine levels are displayed in pg/mL. Analyses were performed using the Wilcoxon matched-pairs signed-rank test. $P$ values $<0.05$ are considered statistically significant. ${ }^{*} P<0.05 ; * * P<0.01$. IGF1, insulin-like growth factor 1; IL, interleukin; LPS, lipopolysaccharide; MEK, MAPK/extracellular signal-regulated kinase; PERK, phosphorylated extracellular signal-regulated kinase; RPMI, Roswell Park Memorial Institute (medium); tERK, total ERK; TNF alpha, tumour necrosis factor alpha; U0126, MEK-inhibitor U0126. findings suggest that IGF1, rather than GH, contributes to the increased inflammatory status and the inflammationrelated complications in a state of GH excess.

Interestingly, IGF1 not only influenced monocytederived cytokines, but also potentiated the production of IFNg, a T cell-derived pro-inflammatory cytokine. The fact that stimulation with a naturally occurring colonizer such as C. albicans increases IFNg production is in line with a previous study that found increased IFNg production in mononuclear cells after stimulation with IGF1 and PHA (Tu et al. 1999).

Besides Th1, other lymphocyte subsets, such as the more recently described Th17, also release important proinflammatory cytokines (Park et al. 2005). Th17 produces IL17 and IL22, two important regulatory cytokines for inflammation and atherosclerosis (Liang et al. 2006). In our study, production of these cytokines was not influenced by IGF1. This is in line with our observation that IGF1 stimulation does not affect IL1B production, since IL1B is crucial for the induction of Th17 responses (Dinarello 2011). These data suggest that the effects of IGF1 are not indiscriminate, but rather specific, in targeting certain cytokine responses.

In addition to analysis of pro-inflammatory cytokines, we also assessed the impact of IGF1 on the production of the anti-inflammatory cytokine IL10, which was also potentiated by IGF1 stimulation. This is possibly a counteracting mechanism for some of the proinflammatory effects of IGF1 (Spitz et al. 2016).

It is also important to underline that, in agreement with previous reports ( $\mathrm{Tu}$ et al. 1999, Kooijman et al. 2002, Himpe et al. 2008), IGF1 did not induce cytokine production by itself, while it potentiated cytokine production induced by microbial TLR ligands. This suggests that a combination of ligands is needed to obtain the inflammatory effects of IGF1. The inflammatory effects of IGF1 are very relevant in the context of the metabolic and cardiovascular complications of acromegaly, since TNF alpha, IL6 and IFNg all contribute to the pathophysiology of atherosclerosis in vivo (Hansson \& Libby 2006, Hansson et al. 2006, Moss \& Ramji 2015, Ridker 2016). In addition, the TLR ligands LPS (part of the outer membrane of Gram negative bacteria in the gut) and C. albicans (naturally colonizing yeast) can also be found in the in vivo situation (Raetz \& Whitfield 2002, Kumamoto 2011). We chose to stimulate the PBMCs with TLR 2/4 ligands because TLRs represent a major signalling pathway that triggers inflammation; the human body 
contains an abundance of endogenous TLR 2/4 ligands, including degraded extracellular matrix components, extracellular heat shock proteins, high mobility group box 1, oxLDL and extracellular nuclear materials (Kawai \& Akira 2010). These ligands are released as a result of cell death or injury. This suggests that TLR signalling is the most likely mediator of inflammation.

Additionally, we investigated the mechanisms through which IGF1 exerts these effects on cytokine production. LPS and P3C signalling in PBMC is mediated though TLR4 and TLR2, respectively, which are both important receptors in the pathogenesis of atherosclerosis (Moghimpour Bijani et al. 2012). TLRs induce downstream signalling pathways including PI3K/Akt/mTOR and MAPK, which are reported to induce cytokine production via NFkB signalling (Takeda et al. 2003, Luyendyk et al. 2008). The IGF1 receptor shares these downstream targets with TLRs (Taniguchi et al. 2006, Youngren 2007). However, in our model, inhibition of the Akt/mTOR pathway by rapamycin did not influence the effects of IGF1 significantly, suggesting that a different pathway is involved. MAPK signalling is reported to mediate both IGF-initiated responses and TNF alpha/IL6 production in PBMCs (Liu et al. 2003, Olsnes et al. 2011), whereby activation of MAPK increases pro-inflammatory cytokine production. In line with this, both LPS-induced and LPS/ IGF1-induced cytokine production and pERK expression were significantly attenuated by a MEK inhibitor. However, the reduction in cytokine production and pERK expression was more pronounced after co-stimulation with IGF1 and LPS compared to LPS. This suggests that the synergistic effects of IGF1 on TLR stimulation are, at least partially, mediated through MAPK signalling. The MAPK signalling pathway is also an important pathway in the development of atherosclerosis (Muslin 2008).

In contrast to IGF1, stimulation of PBMCs with GH neither influences basal nor TLR ligand-induced cytokine production in PBMCs from healthy donors. While this is supported by some earlier research (Zarkesh-Esfahani et al. 2000), others reported that GH increased the production of IFNg and IL1B in murine peritoneal macrophages (Sodhi \& Tripathi 2008). Haeffner and coworkers report an inhibitory effect on TNF alpha secretion in monocytes and macrophages stimulated with both GH and LPS (Haeffner et al. 1997). Differences in the experimental models, as well as differences between species (humans in our study vs mice in other reports) are likely to account for these differences.

Our ex vivo model is characterized by a relatively short exposition to GH or IGF1, which does not fully resemble the in vivo situation. Since acromegaly is characterized by a chronic GH and IGF1 excess, we validated our results in PBMC by analysing the cytokine production in stimulated WB obtained from patients with active acromegaly and healthy controls. The IL6 production in WB from acromegaly patients was increased compared to controls. To further validate these findings, stimulation of PBMC obtained from acromegaly patients is needed and to separate the effects of GH and IGF1, combined ex vivo stimulation with GH and IGF1 is necessary. Future studies should also use endogenous ligands that are involved in the pathophysiology of inflammatory diseases, such as oxidized LDL, palmitate (Haversen et al. 2009) or heat shock proteins (Steinberg \& Witztum 2010, Tamura et al. 2012). Furthermore, a more comprehensive analysis on the activation of molecular pathways that are involved in GH/IGF1 signalling and inflammation will provide additional information about the underlying mechanisms.

In conclusion, IGF1, but not GH, has important potentiating effects on the production of specific proinflammatory cytokines in PBMC ex vivo. In addition, stimulation of WB from acromegaly patients results in a more pronounced increase in IL6 production compared to controls. Our data suggest that IGF1 excess induces proinflammatory cytokine production in circulating immune cells, and thereby potentiates the effect of endogenous TLR ligands. This effect is suggested to be mediated via the MAPK pathway and can possibly explain the increased cardiovascular risks in acromegaly. Therefore, targeting both IGF1 overproduction and systemic inflammation seems a possible future approach to reduce cardiovascular morbidity in acromegaly. Further research is needed to elucidate the mechanisms and consequences of GH/IGF1 excess, both ex vivo as in vivo.

Declaration of interest

The authors declare that there is no conflict of interest that could be perceived as prejudicing the impartiality of the research reported.

\section{Funding}

This work was supported by an unrestricted grant from Ipsen Pharmaceuticals.

\section{Acknowledgements}

The authors would like to thank CDCC van der Heijden; N P Riksen and $\mathrm{J} M$ Ratter, for their help with the design and the experiments.

Published by Bioscientifica Ltd. 


\section{References}

Akira S 2001 Toll-like receptors and innate immunity. Advances in Immunology 78 1-56.

Arikan S, Bahceci M, Tuzcu A \& Gokalp D 2009 Serum tumour necrosis factor-alpha and interleukin-8 levels in acromegalic patients: acromegaly may be associated with moderate inflammation. Clinical Endocrinology 70 498-499. (doi:10.1111/j.1365-2265.2008.03362.x)

Che W, Lerner-Marmarosh N, Huang Q, Osawa M, Ohta S, Yoshizumi M, Glassman M, Lee JD, Yan C, Berk BC, et al. 2002 Insulin-like growth factor-1 enhances inflammatory responses in endothelial cells: role of Gab1 and MEKK3 in TNF-alpha-induced c-Jun and NF-kappaB activation and adhesion molecule expression. Circulation Research 90 1222-1230. (doi:10.1161/01. RES.0000021127.83364.7D)

Dekkers OM, Biermasz NR, Pereira AM, Romijn JA \& Vandenbroucke JP 2008 Mortality in acromegaly: a metaanalysis. Journal of Clinical Endocrinology and Metabolism 93 61-67. (doi:10.1210/jc.2007-1191)

Dinarello CA 2011 Interleukin-1 in the pathogenesis and treatment of inflammatory diseases. Blood 117 3720-3732. (doi:10.1182/blood2010-07-273417)

Endres S, Ghorbani R, Lonnemann G, van der Meer JW \& Dinarello CA 1988 Measurement of immunoreactive interleukin-1 beta from human mononuclear cells: optimization of recovery, intrasubject consistency, and comparison with interleukin-1 alpha and tumor necrosis factor. Clinical Immunology and Immunopathology 49 424-438. (doi:10.1016/0090-1229(88)90130-4)

Haeffner A, Thieblemont N, Deas O, Marelli O, Charpentier B, Senik A, Wright SD, Haeffner-Cavaillon N \& Hirsch F 1997 Inhibitory effect of growth hormone on TNF-alpha secretion and nuclear factorkappaB translocation in lipopolysaccharide-stimulated human monocytes. Journal of Immunology 158 1310-1314.

Hansson GK \& Libby P 2006 The immune response in atherosclerosis: a double-edged sword. Nature Reviews Immunology 6 508-519. (doi:10.1038/nri1882)

Hansson GK, Robertson AK \& Soderberg-Naucler C 2006 Inflammation and atherosclerosis. Annual Review of Pathology 1 297-329. (doi:10.1146/annurev.pathol.1.110304.100100)

Haversen L, Danielsson KN, Fogelstrand L \& Wiklund O 2009 Induction of proinflammatory cytokines by long-chain saturated fatty acids in human macrophages. Atherosclerosis 202 382-393. (doi:10.1016/j. atherosclerosis.2008.05.033)

Higashi Y, Quevedo HC, Tiwari S, Sukhanov S, Shai SY, Anwar A \& Delafontaine P 2014 Interaction between insulin-like growth factor-1 and atherosclerosis and vascular aging. Frontiers of Hormone Research 43 107-124. (doi:10.1159/000360571)

Himpe E, Degaillier C, Coppens A \& Kooijman R 2008 Insulin-like growth factor-1 delays Fas-mediated apoptosis in human neutrophils through the phosphatidylinositol-3 kinase pathway. Journal of Endocrinology 199 69-80. (doi:10.1677/JOE-08-0028)

Hirschfeld M, Weis JJ, Toshchakov V, Salkowski CA, Cody MJ, Ward DC, Qureshi N, Michalek SM \& Vogel SN 2001 Signaling by toll-like receptor 2 and 4 agonists results in differential gene expression in murine macrophages. Infection and Immunity 69 1477-1482. (doi:10.1128/IAI.69.3.1477-1482.2001)

Imperlini E, Spaziani S, Mancini A, Caterino M, Buono P \& Orru S 2015 Synergistic effect of DHT and IGF-1 hyperstimulation in human peripheral blood lymphocytes. Proteomics 15 1813-1818. (doi:10.1002/pmic.201400242)

Kawai T \& Akira S 2010 The role of pattern-recognition receptors in innate immunity: update on Toll-like receptors. Nature Immunology 11 373-384. (doi:10.1038/ni.1863)

Kooijman R \& Coppens A 2004 Insulin-like growth factor-I stimulates IL-10 production in human T cells. Journal of Leukocyte Biology $\mathbf{7 6}$ 862-867. (doi:10.1189/jlb.0404248)
Kooijman R, Coppens A \& Hooghe-Peters E 2002 Igf-I inhibits spontaneous apoptosis in human granulocytes. Endocrinology 143 1206-1212. (doi:10.1210/endo.143.4.8725)

Kooijman R, Willems M, De Haas CJ, Rijkers GT, Schuurmans AL, Van Buul-Offers SC, Heijnen CJ \& Zegers BJ 1992 Expression of type I insulin-like growth factor receptors on human peripheral blood mononuclear cells. Endocrinology 131 2244-2250. (doi:10.1210/ endo.131.5.1425423)

Kumamoto CA 2011 Inflammation and gastrointestinal Candida colonization. Current Opinion in Microbiology 14 386-391. (doi:10.1016/j.mib.2011.07.015)

Lehrer RI \& Cline MJ 1969 Interaction of Candida albicans with human leukocytes and serum. Journal of Bacteriology 98 996-1004.

Liang SC, Tan XY, Luxenberg DP, Karim R, Dunussi-Joannopoulos K, Collins M \& Fouser LA 2006 Interleukin (IL)-22 and IL-17 are coexpressed by Th17 cells and cooperatively enhance expression of antimicrobial peptides. Journal of Experimental Medicine $\mathbf{2 0 3}$ 2271-2279. (doi:10.1084/jem.20061308)

Liu E, Law HK \& Lau YL 2003 Insulin-like growth factor I promotes maturation and inhibits apoptosis of immature cord blood monocyte-derived dendritic cells through MEK and PI 3-kinase pathways. Pediatric Research 54 919-925. (doi:10.1203/01. PDR.0000088067.04673.1B)

Luyendyk JP, Schabbauer GA, Tencati M, Holscher T, Pawlinski R \& Mackman N 2008 Genetic analysis of the role of the PI3K-Akt pathway in lipopolysaccharide-induced cytokine and tissue factor gene expression in monocytes/macrophages. Journal of Immunology 180 4218-4226. (doi:10.4049/jimmunol.180.6.4218)

Moghimpour Bijani F, Vallejo JG \& Rezaei N 2012 Toll-like receptor signaling pathways in cardiovascular diseases: challenges and opportunities. International Reviews of Immunology 31 379-395. (doi:10.3109/08830185.2012.706761)

Moss JW \& Ramji DP 2015 Interferon-gamma: promising therapeutic target in atherosclerosis. World Journal of Experimental Medicine $\mathbf{5}$ 154-159. (doi:10.5493/wjem.v5.i3.154)

Muslin AJ 2008 MAPK signalling in cardiovascular health and disease: molecular mechanisms and therapeutic targets. Clinical Science $\mathbf{1 1 5}$ 203-218. (doi:10.1042/CS20070430)

Netea MG, Gow NA, Munro CA, Bates S, Collins C, Ferwerda G, Hobson RP, Bertram G, Hughes HB, Jansen T, et al. 2006 Immune sensing of Candida albicans requires cooperative recognition of mannans and glucans by lectin and Toll-like receptors. Journal of Clinical Investigation 116 1642-1650. (doi:10.1172/JCI27114)

Olsnes C, Olofsson J \& Aarstad HJ 2011 MAPKs ERK and p38, but not JNK phosphorylation, modulate IL-6 and TNF-alpha secretion following OK-432 in vitro stimulation of purified human monocytes. Scandinavian Journal of Immunology 74 114-125. (doi:10.1111/ j.1365-3083.2011.02555.x)

Park H, Li Z, Yang XO, Chang SH, Nurieva R, Wang YH, Wang Y, Hood L, Zhu Z, Tian Q et al. 2005 A distinct lineage of CD4 T cells regulates tissue inflammation by producing interleukin 17 . Nature Immunology 6 1133-1141. (doi:10.1038/ni1261)

Raetz CR \& Whitfield C 2002 Lipopolysaccharide endotoxins. Annual Review of Biochemistry 71 635-700. (doi:10.1146/annurev. biochem.71.110601.135414)

Renier G, Clement I, Desfaits AC \& Lambert A 1996 Direct stimulatory effect of insulin-like growth factor-I on monocyte and macrophage tumor necrosis factor-alpha production. Endocrinology 137 4611-4618. (doi:10.1210/endo.137.11.8895324)

Ridker PM 2016 From C-reactive protein to Interleukin-6 to Interleukin-1: moving upstream to identify novel targets for atheroprotection. Circulation Research 118 145-156. (doi:10.1161/ CIRCRESAHA.115.306656)

Robertson AK \& Hansson GK 2006 T cells in atherogenesis: for better or for worse? Arteriosclerosis, Thrombosis, and Vascular Biology 26 2421-2432. (doi:10.1161/01.ATV.0000245830.29764.84)

Published by Bioscientifica Ltd 
Sodhi A \& Tripathi A 2008 Prolactin and growth hormone induce differential cytokine and chemokine profile in murine peritoneal macrophages in vitro: involvement of p-38 MAP kinase, STAT3 and NF-kappaB. Cytokine 41 162-173. (doi:10.1016/j.cyto.2007.11.007)

Spitz C, Winkels H, Burger C, Weber C, Lutgens E, Hansson GK \& Gerdes N 2016 Regulatory T cells in atherosclerosis: critical immune regulatory function and therapeutic potential. Cellular and Molecular Life Sciences 73 901-922. (doi:10.1007/s00018-0152080-2)

Steinberg D \& Witztum JL 2010 Oxidized low-density lipoprotein and atherosclerosis. Arteriosclerosis, Thrombosis, and Vascular Biology 30 2311-2316. (doi:10.1161/ATVBAHA.108.179697)

Takeda K, Kaisho T \& Akira S 2003 Toll-like receptors. Annual Review of Immunology 21 335-376. (doi:10.1146/annurev. immunol.21.120601.141126)

Tamura Y, Torigoe T, Kutomi G, Hirata K \& Sato N 2012 New paradigm for intrinsic function of heat shock proteins as endogenous ligands in inflammation and innate immunity. Current Molecular Medicine 12 1198-1206. (doi:10.2174/156652412803306710)

Taniguchi CM, Emanuelli B \& Kahn CR 2006 Critical nodes in signalling pathways: insights into insulin action. Nature Reviews Molecular Cell Biology 7 85-96. (doi:10.1038/nrm1837)

Touskova V, Trachta P, Kavalkova P, Drapalova J, Haluzikova D, Mraz M, Lacinova Z, Marek J \& Haluzik M 2012 Serum concentrations and tissue expression of components of insulin-like growth factor-axis in females with type 2 diabetes mellitus and obesity: the influence of very-low-calorie diet. Molecular and Cellular Endocrinology 361 172-178. (doi:10.1016/j.mce.2012.04.005)

Tu W, Cheung PT \& Lau YL 1999 IGF-I increases interferon-gamma and IL-6 mRNA expression and protein production in neonatal mononuclear cells. Pediatric Research 46 748-754 (doi:10.1203/00006450-199912000-00019)

Ucler R, Aslan M, Atmaca M, Alay M, Ademoglu EN \& Gulsen I 2015 Evaluation of blood neutrophil to lymphocyte and platelet to lymphocyte ratios according to plasma glucose status and serum insulin-like growth factor 1 levels in patients with acromegaly. Human and Experimental Toxicology 46 748-748. (doi:10.1203/00006450-199912000-00019)

van Crevel R, van der Ven-Jongekrijg J, Netea MG, de Lange W, Kullberg BJ \& van der Meer JW 1999 Disease-specific ex vivo stimulation of whole blood for cytokine production: applications in the study of tuberculosis. Journal of Immunology Methods 222 145-153. (doi:10.1016/S0022-1759(98)00192-6)

van der Graaf CA, Netea MG, Verschueren I, van der Meer JW \& Kullberg BJ 2005 Differential cytokine production and Toll-like receptor signaling pathways by Candida albicans blastoconidia and hyphae. Infection and Immunity 73 7458-7464. (doi:10.1128/ IAI.73.11.7458-7464.2005)

Weigent DA 2013 Lymphocyte GH-axis hormones in immunity. Cellular Immunology 285 118-132. (doi:10.1016/j.cellimm.2013.10.003)

Youngren JF 2007 Regulation of insulin receptor function. Cellular and Molecular Life Sciences 64 873-891. (doi:10.1007/s00018-007-6359-9)

Zarkesh-Esfahani SH, Kolstad O, Metcalfe RA, Watson PF, von Laue S, Walters S, Revhaug A, Weetman AP \& Ross RJ 2000 High-dose growth hormone does not affect proinflammatory cytokine (tumor necrosis factor-alpha, interleukin-6, and interferon-gamma) release from activated peripheral blood mononuclear cells or after minimal to moderate surgical stress. Journal of Clinical Endocrinology and Metabolism 85 3383-3390. (doi:10.1210/ jcem.85.9.6823)

Received in final form 16 May 2017

Accepted 13 June 2017

Accepted Preprint published online 13 June 2017
(C) 2017 Society for Endocrinology Printed in Great Britain 